\title{
Corn silk induces nitric oxide synthase in murine macrophages
}

\author{
Kyung A Kim ${ }^{1}$, Sang-Kyu Choi ${ }^{1}$ \\ and Hye-Seon $\mathrm{Choi}^{1,2}$ \\ ${ }^{1}$ Department of Biological Sciences \\ the Immunomodulation Research Center \\ University of Ulsan, Ulsan 680-749, Korea \\ ${ }^{2}$ Corresponding author: Tel, 82-52-259-1545; \\ Fax, 82-52-259-1694; E-mail, hschoi@mail.ulsan.ac.kr
}

Accepted 22 November 2004

Abbreviations: HRP, horseradish peroxidase; iNOS, inducible nitric oxide synthase; NF-KB, nuclear factor kappa B; NO, nitric oxide; PDTC, pyrolidine dithiocarbamate

\begin{abstract}
Corn silk has been purified as an anticoagulant previously and the active component is a polysaccharide with a molecular mass of $135 \mathrm{kDa}$. It activates murine macrophages to induce nitric oxide synthase (NOS) and generate substantial amounts of $\mathrm{NO}$ in time and dose-dependent manners. It was detectable first at $15 \mathrm{~h}$ after stimulation by corn silk, peaked at $24 \mathrm{~h}$, and undetectable by $48 \mathrm{~h}$. Induction of NOS is inhibited by pyrolidine dithiocarbamate (PDTC) and genistein, an inhibitor of nuclear factor kappa $B$ (NF-KB) and tyrosine kinase, respectively, indicating that iNOS stimulated by corn silk is associated with tyrosine kinase and NF-KB signaling pathways. IKB- $\alpha$ degradation was detectible at $10 \mathrm{~min}$, and the level was restored at $120 \mathrm{~m}$ in after treatment of corn silk. Corn silk induced nuclear translocation of NF-KB by phosphorylation and degradation of $I \kappa B-\alpha$.
\end{abstract}

Keywords: macrophages; nitric oxide; nitric oxide synthase; NF-KB

\section{Introduction}

Corn silk is an outer thread-like part of corn. It has been used to treat a pathological swelling and asthma, and used for diuretics in oriental medicine. Although recently more interests have been focused on biological activities of medicinal plants, most researches are still in the preliminary stage. Methanol extracts of corn silk showed an antioxidative activity on the level of lipid peroxidation (Maksimovic and Kovacevic, 2003). Volatiles from corn silk inhibited the growth of Aspergillus flavus, indicating that it has an antifungal activity (Ziringue, 2000). In addition, extract of corn silk inhibited TNF and LPS-induced cell adhesion, but not cytotoxic activity or TNF production (Habtemariam, 1998).

Macrophages play key roles during immune response after activation (Caleda and Nathan, 1994). A variety of mechanisms can activate macrophages including exposure to cytokines such as IFN- $\gamma$ and interleukin-2. Macrophage activation can be also stimulated by infection of bacteria, bacterial products, and their particulates. They can destroy tumor cells after treatment with both IFN- $\gamma$ and LPS, indicating that two stimuli are necessary for complete activation (Drysdale et al., 1988). Each molecule interacts with specific receptor on the surface of macrophages (Lorsbach et al., 1993). Macrophages can also kill bacteria, virus, or parasites directly, secrete proinflamatory cytokines, act as an antigen presenting cells, and finally participate in tissue remodeling. Macrophage activation was accompanied by increased cell size, cytoplasmic spreading, increased NO production, increased cytokines and adhesion molecules, and $\mathrm{Fc}$ receptors.

NO has been identified as an important signaling molecule involved in regulating a variety of biological activities. Macrophages release NO from guanidino moiety of L-arginine via reaction catalyzed by the inducible form of nitric oxide synthase (iNOS) by a variety of agents such as endotoxin, IL-1, TNF- $\alpha$, and IFN- $\gamma$ (Chen et al., 1999; Tracey, 2002). A major part of inducible nitric oxide synthase (iNOS) regulation occurs at the transcriptional levels and changes in iNOS mRNA lead to different concentration of NO production in iNOS-expressing cells (Lowenstein et al., 1993; Yang et al., 2002).

Although the signal transduction pathway for iNOS is not yet clear, many researches have been studied for iNOS expression induced by proinflammatroy cytokines. The induction of iNOS is triggered and regulated by a series of signaling pathways including nuclear factor kappa B (NF-kB) transcription factor. The promoter region of the iNOS gene contains several transcription factor binding sites including that for NF-kB (Lowenstein et al., 1993). The transcription factor, NF-KB has been implicated as an essential part of pathogen- and stress-related responses of host organisms. Direct or indirect signals from pathogens or stress potently activated NF-KB, which can 
induce many defense-related genes transcriptionally. The family of NF-KB protein was required for the enhanced iNOS gene expression when macrophages were exposed to LPS and other signals such as serum deprivation (Xie et al., 1994; Liu et al., 2001). In naive cells, NF-KB is associated with an inhibitory protein, $I \kappa B-\alpha$ in the cytoplasm, binding to NF- $\kappa B$ dimers and keeping its inactive state, but activation by appropriate signals leads to the phosphorylation of $\mid \kappa B-\alpha$ by $\mid \kappa B-\alpha$ kinase. Phosphorylated $I \kappa B-\alpha$ is released from NF- $\mathrm{KB}$ complex, allowing the translocation of NF-KB into the nucleus, binding to DNA, and leading to activate the responsive genes (Lin et al., 1995).

In this study, we report that stimulation of macrophages with corn silk induced significant amounts of nitric oxide synthase (NOS) with production of NO. NOS induction was mediated by nuclear translocation of $N F-\kappa B$ by degradation of $\mid \kappa B-\alpha$.

\section{Materials and Methods}

\section{Cells and reagents}

RAW264.7 cells, a murine macrophage cell line, were obtained from the ATCC and cultured in DMEM supplemented with $10 \%$ fetal bovine serum, $100 \mathrm{U} / \mathrm{ml}$ penicillin, $100 \mu \mathrm{g} / \mathrm{ml}$ streptomycin in 6 well plates or in $10 \mathrm{~cm}$ dishes. DMEM, FBS, penicillin, streptomycin, polymyxin B, LPS (from Escherichia coli serotype 055: B5), pyrolidine dithiocarbamate (PDTC), SB203580, PD98059, and genistein were obtained from Sigma Chemical Co. (St. Louis, MO). mAb for iNOS, p50

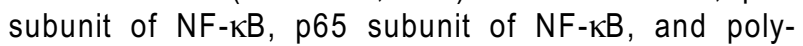
clonal $A b$ for I $K B-\alpha$ were from Santa Cruz Biotechnology (Santa Cruz, CA).

\section{Purification of corn silk active fraction}

Active fraction of corn silk was prepared by the methods of Choi et al. (2004). Corn silk was obtained from local market, washed with distilled water, and disrupted for $5 \mathrm{~min}$ with pulse in an ice-chilled bead-beater (Biospec Products, Bartleville, OK). The homogenate was filtered by several layers of cheese cloths, and the filtrates were centrifuged at $10,000 \mathrm{~g}$ for $40 \mathrm{~min}$ in a refrigerated centrifuge, T-324 using A-8.24 rotor (Kontron Instruments, Zurich, Sweden). The supernatant was fractionated with ethyl acetate, and the aqueous fraction was applied on a Sephadex G-100 column, a phenyl Sepharose column, and finally a Sephadex G-150 column to get a purified fraction. All corn silk preparations were pre-treated with polymyxin B for $2 \mathrm{~h}$ at room temperature to prevent corn silk from endotoxin contamination.

\section{Immunoblot analysis}

Ten $\mu \mathrm{g}$ of cell lysate were separated by SDS-PAGE and transferred onto nitrocellulose membranes as described before (Shin et al., 2002). The blots were then washed in Tris-Tween buffered saline [TTBS, 20 $\mathrm{mM}$ Tris- $\mathrm{HCl}, \mathrm{pH} 7.6$ containing $137 \mathrm{mM} \mathrm{NaCl}$ and $0.05 \%$ (v/v) Tween 20], blocked overnight with $5 \%$ $(\mathrm{w} / \mathrm{v}) \mathrm{BSA}$, and probed with $\mathrm{mAb}$ for iNOS, p50 or p65 NF- $\kappa B$ and polyclonal $A b$ for $1 \kappa B-\alpha$ in $5 \%(\mathrm{w} / \mathrm{v})$ $B S A$ dissolved in TTBS. Using HRP-conjugated secondary anti-mouse Abs (iNOS, p50 or p65 NF-KB), or anti-rabbit $A b(\mid \kappa B-\alpha)$, blots were detected by enhanced chemiluminescence.

\section{Determination of NO concentration}

NO production in culture supernatants was assayed by measuring nitrite, its stable degradation product, using Griess reagent. After stimulation, the supernatants were centrifuged and its aliquots were mixed with $0.25 \mathrm{ml}$ of Griess reagent to make final volume of $0.5 \mathrm{ml}$ and then incubated for $10 \mathrm{~min}$ at room temperature before measuring the absorbance at 540 $\mathrm{nm}$. $\mathrm{NaNO}_{2}$ was used as a standard.

\section{Results}

The anticoagulant was purified and characterized from corn silk (Choi et al., 2004). Since inflammation and coagulation are closely related, we have tested whether it activates macrophages. Macrophages incubated with corn silk expressed high level of iNOS and produced significant amount of $\mathrm{NO}$ in a dose-dependent manner (measured as $\mathrm{NO}_{2}^{-}$)(Figure $1 \mathrm{~A}$ ). Production of NO was detectable at $2.5 \mu \mathrm{g} / \mathrm{ml}$ of corn silk after $24 \mathrm{~h}$ stimulation. Above $25 \mu \mathrm{g} / \mathrm{ml}$ of corn silk activation, the level of NO decreased. The expression of iNOS was also time-dependent. It is detectable first at $15 \mathrm{~h}$ after corn silk activation, remained up to $32 \mathrm{~h}$, and undetectable by $48 \mathrm{~h}$ (Figure 1B). However, released NO was detectable after $8 \mathrm{~h}$ stimulation with corn silk and the level of NO increased up to $48 \mathrm{~h}$. To clarify that NO production and expression of iNOS were due to carbohydrate part of corn silk, corn silk was treated with nonspecific protease, subtilisin $B$, or was oxidized by periodic acid. As shown in Figure $1 \mathrm{C}$, proteasetreated corn silk did not change the level of iNOS expression, whereas oxidized one did not induce NOS at all, indicating that carbohydrate of corn silk is responsible for the stimulation of macrophages. In case of buffered control treated corn silk, the level of iNOS was reduced probably due to loss during oxidation processes.

To determine signaling molecules contributing to 
A
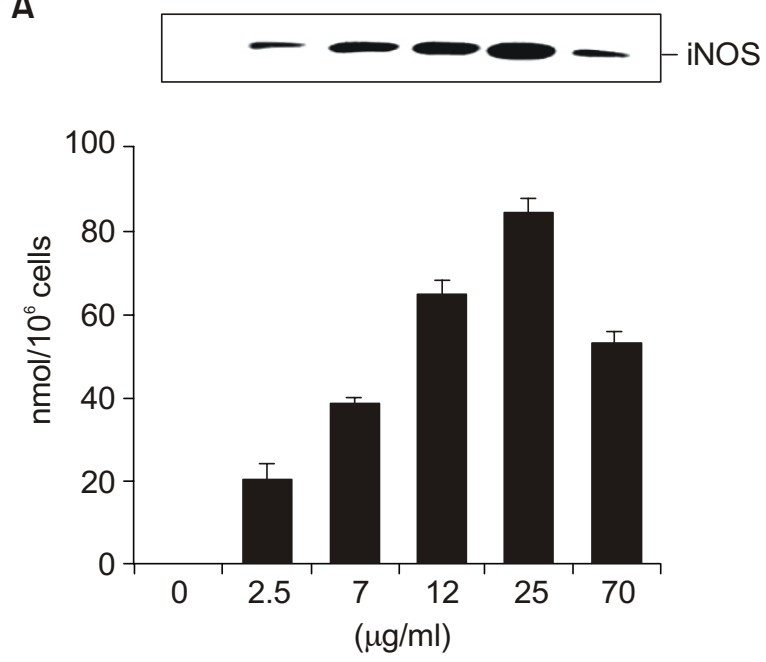

B
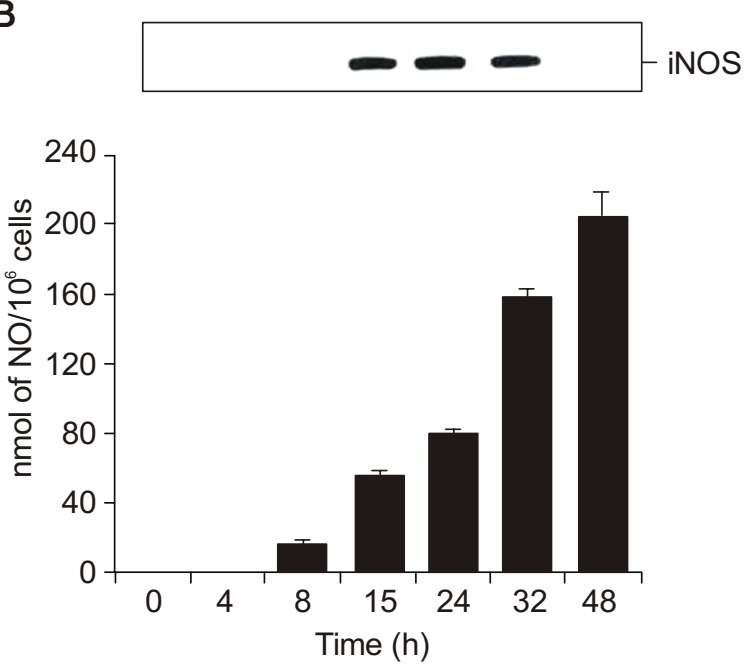

C

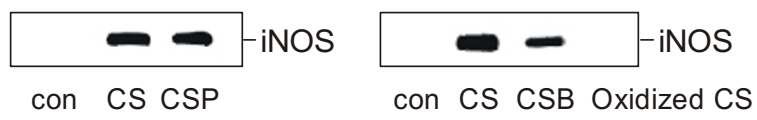

Figure 1. Production of NO by corn silk in RAW 264.7 cells. (A) Cells were treated with corn silk at various concentrations for $24 \mathrm{~h}$, followed by the Griess reagent assay for NO. (B) Cells were treated with 25 $\mu \mathrm{g} / \mathrm{ml}$ of corn silk for indicated incubation times. (C) Cells were treated with $25 \mu \mathrm{g} / \mathrm{ml}$ of corn silk preincubated without (CS) or with subtilisin B (CSP) for $18 \mathrm{~h}$. (D) Corn silk was oxidized with periodate (CSP) for $24 \mathrm{~h}$. CSB was buffer treated instead of periodic acid. Then, cells were incubated with corn silk for $18 \mathrm{~h}$. The data shown represent the mean $\pm S D$ of three independent assays. The cells used in the NO assay were subjected to electrophoresis and Western blot analysis using iNOS-specific $\mathrm{Ab}$ as described in Materials and Methods. Results were representative of three independent experiments.

corn silk-induced iNOS production, we tested the effects of inhibitors of MEK (PD98059), p38 (SB20 3580), tyrosine kinase (genistein), tyrosine phosp- hatase (sodium orthovanadate), and NF-KB (PDTC) on NOS induction by corn silk. Corn silk-induced NOS production was not inhibited by the addition of PD98059 and SB203580, indicating that MEK and p38 MAPK are not involved in signal transduction pathway stimulated by corn silk (Figure 2). However, PDTC and genistein inhibited NOS induction significantly, while sodium orthovanadate potentiated NOS expression (Figure 2). These results suggested that NOS induction stimulated by corn silk is via activation of NF-KB and inhibition of tyrosine phosphatase.

Next, we have determined degradation of IKB- $\alpha$ to investigate the potential role of activation of NF-KB in the expression of iNOS by corn silk in mouse macrophages. The cells were stimulated with corn silk for $0,5,10,15,30,60$, and $120 \mathrm{~min}$. Cells were lysed, fractionated, and analyzed by Western blotting. As shown in Figure $3 \mathrm{~A}$, corn silk induced the degradation of $1 \kappa \mathrm{B}-\alpha$. Degradation of $\mathrm{I} \kappa \mathrm{B}-\alpha$ began at $10 \mathrm{~min}$ after corn silk stimulation, and the level of $\mathrm{I} \kappa$ $B-\alpha$ was restored after $120 \mathrm{~min}$. As a positive control, LPS also showed degradation of $\mathrm{I}$ B $\mathrm{B}-\alpha$, but the time course was different. Next, to examine the effect of corn silk on nuclear translocation of NF-kB, cells were treated 0,60 , and $120 \mathrm{~min}$ with corn silk, and cytoplasmic and nuclear extracts were examined for $p 50$ and $\mathrm{p} 65 \mathrm{NF}-\mathrm{kB}$ by immunoblots. Figure $3 \mathrm{~B}$ showed that corn silk caused nuclear translocation of p50 and p65 subunits after 60 min of corn silk stimulation, and decreased the cytoplasmic levels of these two proteins. Consistent with corn silk-induced degradation of IK $B-\alpha$, it induced nuclear translocation of $p 50$ and p65 NF- $k B$, and caused these proteins to stimulate the responsive gene.

\section{Discussions}

We demonstrated that corn silk extract activates macrophages to express high level of iNOS and generates large amounts of NO in time and dosedependent manners. The corn silk extract was purified and characterized to have an activity of anticoagulation both in human plasma and in thrombininduced purified fibrinogen system (Choi et al., 2004). Since processes of coagulation and inflammation are closely related and share mediators, a possible effect of the anticoagulant from corn silk on macrophages was tested. The anticoagulant from corn silk delayed thrombin time twice at $8.1 \mu \mathrm{g} / \mathrm{ml}$ using human plasma, and analysis of the inhibition of thrombin- catalyzed fibrin formation gave an apparent $K_{i}$ value of 3.1 $\mu \mathrm{g} / \mathrm{ml}$ using purified fibrinogen (Choi et al., 2004). Our data showed that it also activated macrophage and generated $\mathrm{NO}$ at the concentration range of 2.5-70 $\mu \mathrm{g} / \mathrm{ml}$. Its anticoagulating activity occurred at the 

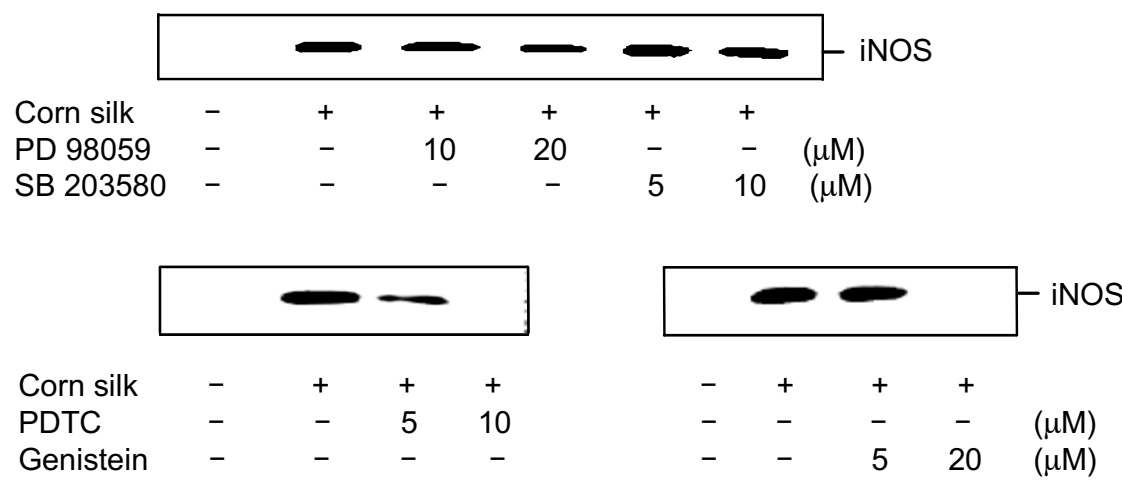

Figure 2. Effects of inhibitors involved in signal transduction pathways on expression of iNOS by corn silk in RAW 264.7 cells. Cells were pretreated with each inhibitor for $1 \mathrm{~h}$, and stimulated with 25 $\mu \mathrm{g} / \mathrm{ml}$ of corn silk for $24 \mathrm{~h}$. The cell lysates were subjected to electrophoresis and Western blot analysis using iNOS-specific $A b$ as described in Materials and Methods. Results were representatives of three independent ex-

$\begin{array}{llllll}\text { Corn silk } & - & + & + & + & \\ \text { Vanadate } & - & - & 10 & 20 & (\mu \mathrm{M})\end{array}$
periments.

A

A

LPS

Corn silk
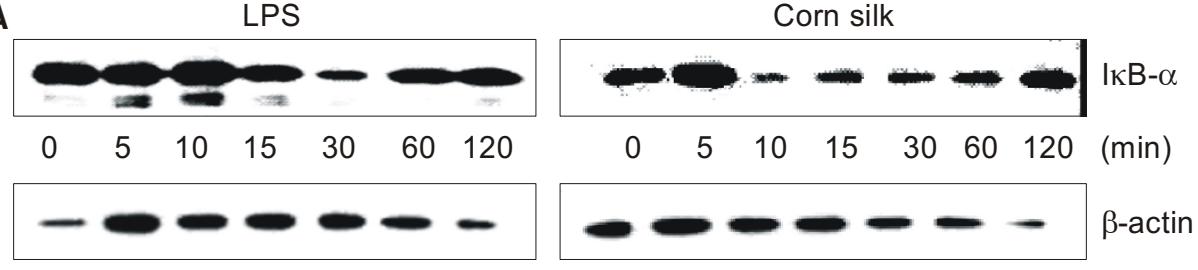

B
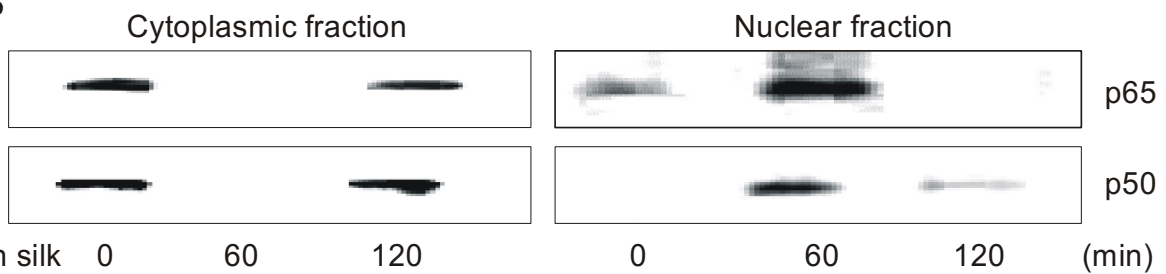

Corn silk 0

60

120

60

(min)

Figure 3. Effects of corn silk on NF-KB signaling pathways in RAW 264.7 cells. (A) Cells were stimulated with $25 \mu \mathrm{g} / \mathrm{ml}$ of corn silk for $0,5,10,15,30,60$, and $120 \mathrm{~min}$. The cytoplasmic fractions of cell lysates were subjected to electrophoresed and Western blot analysis using IkB- $\alpha$ specific $\mathrm{Ab}$ as described in Materials and Methods. LPS (1 $\mu \mathrm{g} / \mathrm{ml})$ was treated as a positive control. (B) Cells were stimulated with $25 \mu \mathrm{g} / \mathrm{ml}$ of corn silk for 0,60, and $120 \mathrm{~min}$. Cells were lysed, and cytoplasmic and nuclear fractions were separated. Cytosols and nuclear extracts were analyzed for $\mathrm{p} 50$ and $\mathrm{p} 65 \mathrm{NF}-\mathrm{KB}$ by immunoblots. Results were representative of three independent experiments.

similar concentration range to its inflammatory activity such as NO production. As bacterial outer shell component, LPS which activates macrophages has a strong stimulatory effect on factor X-activating activities (Pejler, 1999). An activator of coagulation, tissue factor can directly augment macrophage activation by factor VII1-dependent induction of proinflammatory changes in macrophages (Cunningham et al., 1999). Tissue factor also induces arthritis in mice by strong inflammatory properties mediated by monocytes (Bokarewa et al., 2002).
Production of $\mathrm{NO}$ was detectable at $2.5 \mu \mathrm{g} / \mathrm{ml}$ of corn silk and reached at the maximum at $25 \mu \mathrm{g} / \mathrm{ml}$ after $24 \mathrm{~h}$ stimulation. Latter condition was used for following NO production assays. Above $25 \mu \mathrm{g} / \mathrm{ml}$ of corn silk reduced the iNOS level. We have not determined whether corn silk induces other molecules. However, the decrease could be explained by induction of other proteins such as heme oxygenase-1 (Otterbein et al., 2003). Inhibition of NO accumulation by peroxysome proliferator-activated receptor agonists was associated with a fall in inducible NOS protein 
and an induction of heme oxygenase-1 (Colville-Nash et al., 1998).

Activations of NF-KB and inhibition of tyrosine phosphatase were involved in the induction process of NOS in murine macrophages stimulated by corn silk. Through a series of signaling pathways, the activation of the multisubunit inhibitor of $I \kappa B(I \kappa B)$ kinase (IKK) complex induces $I \kappa B \alpha$ and $I \kappa B \beta$ phosphorylation. Phosphorylation of these inhibitory proteins leads to degradation and the release of Rel/ NF- $\mathrm{KB}$ proteins from cytosol to the nucleus. iNOS is among the genes that are induced by $N F-\kappa B$ transcription

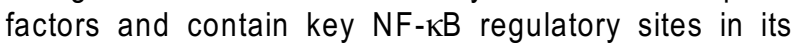
promoter. Although the membrane receptor of corn silk has not been determined yet, certain membrane proteins are assumed to act as a receptor in macrophages. A possible candidate could be CR3 which is identified as the leukocyte membrane receptor for $\beta$-glucan (Thornton et al., 1996). Angelan, a polysaccharide from Angelica gigas, also stimulated macrophages and induced NF-KB in murine macrophages (Jeon and Kim, 2001). Since PDTC, a relatively specific inhibitor of the activation of NF-KB in macrophages, blocked the NOS induction, it appeared that $\mathrm{NF}-\mathrm{KB}$ is involved in the induction of iNOS gene itself in corn silk-stimulated macrophages. However, we have not tested the effects of PDTC on binding of $N F-\kappa B$ proteins to the iNOS promoter. However, we demonstrated that corn silk caused degradation of $1 \kappa \mathrm{B}-\alpha$ in murine macrophages. Corn silk also induced nuclear translocation of p50 and p65 subunits of $N F-\kappa B$ after degradation of $1 \kappa B-\alpha$. Our results strongly suggest that corn silk induced NOS by NF-KB pathway. A role for tyrosine phosphatase in control of iNOS expression was reported in IFN- $\gamma$-treated peritoneal macrophages (Diaz-Guerra et al., 1999). Treatment with sodium orthovanadate of macrophages stimulated with IFN- $\gamma$ potentiated the activation of NF- $\mathrm{KB}$ and the expression of iNOS. Analysis of iNOS promoter activity showed that inhibition of tyrosine phophatase increased the cooperation between IFN- $\gamma$-activated transcription factors and $\mathrm{NF}-\mathrm{KB}$, indicating a negative role for tyrosine phosphatase. Importance of tyrosine phosphatase in the regulation of iNOS was also reported in Leishmania-infected macrophages (Nandan et al., 1999). Infection with Leishmania attenuated iNOS expression with reduced MAPK signaling and it was recovered by treatment of sodium orthovanadate.

In summary, we have shown that corn silk activates macrophages to express NOS via NF-KB and tyrosine kinase activation. Corn silk induced nuclear translocation of $\mathrm{p} 50$ and $\mathrm{p} 65$ subunits of NF-KB after degradation of $I \kappa B \alpha$.

\section{Acknowledgement}

This work was supported by Research Fund 2004 of University of Ulsan. K.A Kim was supported by BK21 of UOU (2003-2005).

\section{References}

Bokarewa MI, Morrissey JH, Tarkowski A. Tissue factor as a proinflammatory agent. Arthritis Res 2002;4:190-5

Caleda A, Nathan CF. Macrophages activation revisited. Immunol Today 1994;15:100-2

Chen CC, Chiu KT, Sun YT, Chen WC. Role of the cyclic AMP-protein kinase A pathway in lipopolysaccharide-induced nitric oxide synthase expression in RAW 264.7 macrophage. J Biol Chem 1999;274:31559-64

Choi SK, Choi HS. Purification and characterization of an anticoagulant from corn silk. J Kor Soc Food Sci Nutr 2004; 33:1262-7

Colville-Nash PR, Qureshi SS, Willis D, Willoughby DA. Inhibition of inducible nitric oxide synthase by peroxysome proliferator-activated receptor agonists: correlation with induction of heme oxygenase 1. J Immunol 1998;161: 978-84

Cunningham MA, Romas $P$, Hutchinson $P$, Holdsworth SR, Tipping PG. Tissue factor and factor VIla receptor/ligand interactions induce proinflammatory effects in macrophages. Blood 1999;94:3413-20

Diaz-Guerra MJ, Castrillo A, Martin-Sanz P, Bosca L. Negative regulation by protein tyrosine phosphatase of IFN-gamma-dependent expression of inducible nitric oxide synthase. J Immunol 1999;162:6776-83

Drysdale BE, Argawal S, Shin HS. Macrophage-mediated tumorcidal and activity: mechanisms of activation and cytotoxicity. Prog Allergy 1988;40:111-61

Habtemariam S. Extracts of corn silk inhibits the tumor necrosis factor-alpha- and bacterial lipopolysaccharideinduced cell adhesion and ICAM-1 expression. Planta Med 1998;64:314-8

Jeon YJ, Kim HM. Experimental evidences and signal transduction pathways involved in the activation of /Rel by angelan in murine macrophages. Int Immunopharm 2001; $1: 1331-9$

Lin $\mathrm{Y}$, Brown $\mathrm{K}$, Siebenlist $U$. Activation of $N F-\kappa B$ requires proteolysis of the inhibitor of $1 \kappa B-\alpha$ : Signal-induced phosphorylation of $I \kappa B-\alpha$ alone does not release active NF-KB. Proc Natl Acad Sci USA 1995;92:552-6

Liu W, Kato M, Itoigawa M, Murakami H, Yajima M, Wu J, Ishikawa N, Nakashima I. Distinct involvement of NF- $\mathrm{KB}$ and p38 mitogen-activated protein kinase pathways in serum deprivation mediated stimulation of inducible nitric oxide synthase and its inhibition by 4-hydroxynonenal. J Cell Biochem 2001;83:271-80

Lorsbach RB, Murphy WJ, Lowenstein CJ, Snyder SH, Russel SW. Expression of nitric oxide synthase gene in mouse macrophages activated for tumor cell killing. J Biol 
Chem 1993;268:1908-13

Lowenstein CL, Alley EW, Ravel P, Snowman AM, Sydner $\mathrm{SH}$, Russell SW, Murphy WJ. Macrophage nitric oxide synthase gene: two upstream regions mediate induction by interferon gamma and lipopolysaccharide. Proc Natl Acad Sci USA 1993;90:9730-4

Maksimovic ZA, Kovacevic N. Preliminary assay on the antioxidative activity of Maydis stigma extracts. Fitoterapia 2003;74:144-7

Nandan D, Lo R, Reiner NE. Activation of phosphotyrosine phosphatase activity attenuates mitogen-activated protein kinase signaling and inhibits c-FOS and nitric oxide synthase expression in macrophages infected with Leishmania donovani. Infect Immun 1999;67:4055-63

Otterbein LE, Soares MP, Yamashita K, Bach FH. Heme oxygenase-1: unleashing the protective properties of heme. Trends Immunol 2003;24:449-55

Pejler G. Procoagulant and anticoagulant activities of resident and inflammatory peritoneal cells. Inflamm Res 1999;48: $344-50$
Shin HH, Lee MH, Kim SK, Kwon B, Choi HS. Recombinant glucocorticoid induced tumor necrosis factor receptor (rGITR) induces NOS in murine macrophage. FEBS Lett 2002;514: $275-80$

Thornton BP, Vetvicka V, Pitman M, Goldman RC, Ross GD. Analysis of the sugar specificity and molecular location of the $\beta$-glucan-binding lectin site of complement receptor type 3. J Immunol 1996;156:1235-46

Tracey KJ. The inflammatory reflex. Nature 2002;420:853-9

Xie QW, Kashiwabara $Y$, Nathan C. Role of transcription factor NF-kappa B/Rel in induction of nitric oxide synthase. J Biol Chem 1994;269:4705-8

Yang JY, Koo BS, Kang MK, Rho HW, Sohn HS, Jhee EC, Park JW. Retinoic acid inhibits inducible nitric oxide synthase expression in 3T3-L1 adipocytes. Exp Mol Med 2002;34: $353-60$

Ziringue $\mathrm{HJ}$. Identification and effects of maize silk volatiles on cultures of Aspergillus flavus. J Agric Food Chem 2000; 48:921-5 